\title{
Sustainability Development of Employee Using Kaizen
}

\author{
Muhammad Iqbal Arrasyid ${ }^{1}$, Amaliyah Amaliyah ${ }^{2}$ \\ \{iqbal.arrasyid@gmail.com ${ }^{1}$, amaliyah@trilogi.ac.id ${ }^{2}$ \} \\ ${ }^{1}$ Master Student of Economics and Business Department, Universitas Trilogi, Indonesia \\ ${ }^{2}$ Economics and Business Department, Universitas Trilogi, Indonesia
}

\begin{abstract}
This study aims to describe the pattern of employee sustainability development using Kaizen. The main purpose of employee development is as an effort to deal with the change of companies' competition that potentially changes the company's purposes. This study uses qualitative approach and focuses on the employee sustainability development using Kaizen. This study shows that Kaizen is a process-oriented system used to implement the smallest suggestion from an employee as a small step of improvement. Thus, consistency and sustainability are also considered important in the implementation of Kaizen. The companies that adopted Kaizen consistently will experience a better improvement due to the concept of $3 \mathrm{M}, 3 \mathrm{~S}$, and PDCA. This study also provides recommendation for the top management of companies in applying Kaizen to develop employees' sustainability in order to deal with global competition.
\end{abstract}

Keywords: Kaizen, 3M, 5S, ODCA, Change of vision

\section{Introduction}

The era of globalisation is increasingly showing its influence in all areas of human life. Such rapid advancements in technology and information have an impact on the systems and governance run by companies [1]. Governance in this case includes the development of human resources as an important element in running the company [2]. Globalisation has influenced the management of human resources where business competition does not only cover the intercity within a country but the global competition.

The dynamism of the competitive business climate in the midst of modernization requires companies to be able to make adjustments in order to survive. The next step is to change the company's goal to improve the company's optimisation. Changes in company objectives are closely related to changes in internal components of the company; especially in the human resources. The company is considered successful if it can survive in any condition and situation by managing the human resources effectively and efficiently according to achievement targets $[3,4]$. The human resources management includes the competencies that must be possessed by the employees in order to achieve the company's goals.

Competence of human resources in achieving company goals includes knowledge related to business direction, duties and job responsibilities as well as ability for self-development [5]. Self-development is one of the ways to prepare for changes in corporate goals that may occur at any time. Achieving competent human resources requires competence development, however the more important thing to do prior to the development is to conduct an evaluation, therefore it can later be used to determine the need to improve employees' ability.

Employees' skills can be improved by providing appropriate training based on the analysis of the competencies that employees need to possess [2, 5]. Training is a 
systematically arranged activity by setting goals and standards of achievement given to individuals to improve the knowledge, skills and attitudes needed for work [6]. Training provided to employees has to be adjusted to the development needs, thus it needs to be upgraded continuously and sustainable in order to compensate for changes in company's goals. One of the methods or perspective of sustainable development is kaizen.

Kaizen is a method of continuous development focused mainly on process only, in contrast to the way of western countries that use the result as an indicator [7]. The philosophy of kaizen considers that the human way of life as well as work life and other social life should be focused on continuous improvement efforts, even on a small scale. The work culture of kaizen is considered as the key of most Japanese companies' success [8]. Toyota, for instance, has played a major role in the success of Japanese companies in the world. Toyota is the first company known to implement kaizen system. Toyota is increasingly recognised as one of the automotive companies with remarkable survival ability which proven by the existence of Toyota's vehicles in the world. Due to this reason, many foreign companies apply kaizen working culture in their company.

Companies around the world recognise that kaizen have a good impact to the company's improvement. Furthermore, it cannot be separated from the three main concepts in kaizen which are $3 \mathrm{M}$ concept, 5S movement and PDCA concept. The concept in kaizen generally emphasises the ongoing and continuous planning, implementation and evaluation. It is considered appropriate for the employees' development to address the current business competition climate where changes can quickly occur. Employees' development is accomplished by applying continuous improvements since the changes can occur suddenly in the workplace.

This phenomenon indicates that employees' development is important for the companies because business competition tends to be dynamic. Employees' development cannot be done quickly like setting a machine but it needs to be sustainable, thus that kaizen can be utilised for that matter. Through literature review, this research aims to reveal the pattern of continuous employee development using kaizen.

\section{The Principles of Human Resources Development}

Employees of a company are important resources or assets to achieve company goals [1]. This is because employees play a role to facilitate the activities that exist in the company, such as planning and executing company strategy [4]. The existence of human resources within a company requires a human resources management [3]. Human resource management is required in the context of complex and changing environments [2]. Therefore, it is necessary to develop human resources that align with company goals that also tend to change.

Human resources development is a series of stages in utilising human potentials effectively and efficiently to improve the quality of an individual [1]. The model of human resource development within the company can be done by analysing and setting objectives of human resources. The next stage is to determine the competence of the human resources to in the form of various proficiencies to improve the quality of human resources [3]. Education and training are some examples of an effort to develop human resources, especially for the development of intellectual ability and human personality aspects.

Human resource development can be done through appraisal approach. [3] The principle of human resource development is based on the human context as a thinking creature, thus human resources can be developed by improving skills through training [2,7]. Training can 
assist employees to perform their duties and responsibilities effectively and efficiently [2]. These results are generally become an objective for the human resources development.

\section{Method}

This study uses a qualitative approach by analyzing several theories where it is a way to evaluate quantitative and qualitative literature so that conclusions can be drawn about the circumstances in the field.

\section{The Role of Kaizen in the Employee Development Sustainability}

Kaizen is a term originated from Japan and it is commonly used by some industries to undertake sustainable development in order to improve company's performance [9]. The word kaizen in Japanese consists of two words which are 'kai' which means to change, while 'zen' means better [10]. Kaizen is simply defined as a change for the better [11]. Furthermore, the concept was developed into 'continuous improvement' or sustainable development, therefore kaizen is interpreted as a concept of change for the better through continuous basis.

Massaki Imai stated that kaizen is the key to the company's success in Japan [8]. Kaizen offers the best method known to improve the company as well as a benchmark of the company's success in Japan. Currently, kaizen has been widely applied everywhere. The method of kaizen includes several aspects, including 3M, 5S Movement and PDCA [12,8].

$3 \mathrm{M}$ includes 'muda', 'mura' and 'muri' $[13,14]$. The intended condition includes the smallest component. The first concept in $3 \mathrm{M}$ is 'muda' which means a reduction of waste or futility, 'mura' which means a reduction of difference and 'muri' means a reduction of tension $[15,8]$.

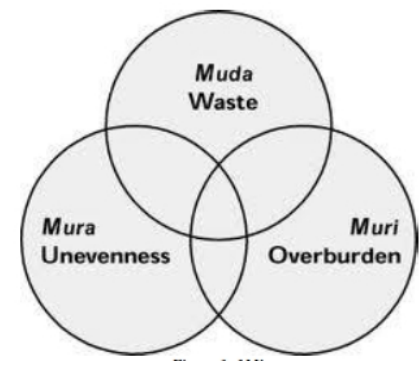

Fig 1. $3 \mathrm{M}$

$3 \mathrm{M}$ can be interpreted as a company has to be able to realise good conditions in order to find the best and most effective solution to any problem [12].

The 5S movement is one of the elements in Kaizen that aims to assess undesirable activity and then replace that activity with more measurable activity to obtain high results in the workplace [16]. 5S components are derived from Japanese terms which include: Seiri, Seiton, Seiso, Seiketsu and Shitsuke [17]. 'Seiri' is an early stage in 5S which means sorting [18]. At this stage, the sorting is done between the required and not required things by the company as well as to reduce data that does not benefit the company's development.

Seiton means setting the placement (set in order). 'Seiton' uses measurable flexibility to make it easy to run [17]. In other words, 'seiton' does not put forward the rules that are too conceptual, complicated and difficult to implement in which the rules are only limited to the theory and disregard the application. 'Seiso' in English terminology is called shine, which is 
interpreted as cleaning [18]. Cleaning in this case is not only about the cleanliness of the workplace [19]. More than that, cleaning in this case includes cleaning up the mess, fix everything and involve in supervision.

'Seiketsu' in English is defined as standardise which means standardisation or determination [16]. After the three elements (seiri, seiton and Seiso) are applied by the company, 3S then must be set as the standard rule imposed on a company [19]. The last one is 'Shitsuke', in English means to sustain. Shitsuke is considered as the most decisive and most difficult stage compared the previous stage [17]. This stage involves behavioural changes that must be adhered, thus high discipline is required to comply with and follow the rules set by the company at all times [19].

The implementation of kaizen in the development of sustainable employees can be verified using the basic behaviour change approach with PDCA [20,4]. PDCA is composed of these words: Plan, Do, Check and Action [4]. PDCA is an activity cycle that enables companies to improve progressive-positive standards [21]. The PDCA cycle is described by Deming as follows:

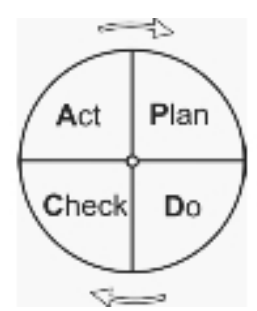

Fig 2. Deming's PDCA cycle

The Plan cycle is a cycle of planning [22]. Planning involves identifying issues related to improvement to achieve the targets [23]. 'Do' can be interpreted as to implement [21]. The Do cycle means to implement predetermined plans based on problem analysis $[22,23]$. The next cycle is 'check' that can be interpreted as an evaluation stage. An evaluation step is taken to ensure the implementation is in compliance with planning and target achievement [21]. After evaluation, the next step is 'action' which is interpreted as a follow-up [23]. Follow-up is done to address the results obtained at the evaluation stage therefore it later can be done through improvement and to avoid the re-occurrence of the same problem.

The philosophy of kaizen comprehensively assumes that workers' lives, both social life and private life deserve to be improved [11,24]. Continuous improvement through the adoption of kaizen theory in a company is a part of the total quality and it is considered a fair to gain more participation and learning from employees in the company [18]. Therefore, the company can work for its external customers. If the company has considered sustainability improvement through Kaizen, then resource empowerment in the company should have a new development system.

The key to the implementation of development in a company is in the authority and responsibility. These are the function of the planning activity that will produce the job description and the task for each division [25]. Continuous or sustainability development involves all stakeholders in the company including top management and employees [26]. Duties and responsibilities of each division are different depending on their position in the company. Each individual in a company is committed to their roles and responsibility related to the competencies to achieve the predetermined target. 
Awareness of the competencies and targets to be achieved raises the gap that can be used as a reference or analysis material in order to determine the type of training needed to improve employees' capabilities [25,6]. The results of training provided by the company will ultimately affect the ability of employees under certain conditions, particularly in the case when the company is in an unstable condition, employees already hold the ability to adjust and respond to the changes. Although the company has changed its objectives, these qualities will retain the company's achievement.

\section{Discussion}

Kaizen is the concept adopted by the company to make changes towards a better condition [24]. The principle of kaizen further evolves into sustainable development which applied to all components and activities of the company. From the top management to employees, everyone carries out the duties and responsibilities according to their position and division together to propose the necessary improvement even if they are small things such as desk or work space arrangement.

Human resources plays an important role for a company's sustainability. It holds control of company's activities especially related to the company's target achievement and missions. Therefore, improvement is required regarding the human resource to fully adjust with dynamic changes.

Based on those various factors, there is a prominent feature of the Kaizen culture that is related to the sustainable improvement, especially the improvement of the capabilities and expertise of human resources (HR) within a company. It is expected to provide positive impact which associated with the development of employees in addressing the dynamics of change. Thus, it later can be synergised in order to achieve company's goals that also undergo changes.

Improvement and development strategies can be measured by two levels: big steps and gradual changes. The big steps include the scope of policies, considerations and responsibilities of the top management. The gradual changes include the efficiency of human resources in the process of activities. The more human resources is involved in the activity process, the lower the value of development and improvement.

The first company who adopted Kaizen system was Toyota, known as TPS (Toyota Production System) [27]. Toyota's success in dominating automotive market was not an easy task. Toyota recognised that the superiors are not always aware of obstacles. In fact, the contribution of employees is required to participate directly in various decisions in order to improve work conditions, considering employees are the subjects involved in every production activities.

Toyota asked employees regularly for ideas by offering compensation in return for any ideas implemented by the company. It still continues thus the suggestions for improvement from employees tend to increase. Up until now, the suggestion system is globally implemented by Toyota on all divisions and it reaches hundreds of thousands suggestions each year. The suggestions or feedback from Toyota employees focus on small issues such as tool setup, the addition of a small footing to streamline the taking of notes and the use of a stroller in order to manoeuvre around the unassembled cars.

Kaizen has the core concept of "work smart", not "work hard" as well as Toyota's operational activities, for example to increase production. In Kaizen, there is no need to increase time and labour, but it does produce a decent quality product in larger quantities using existing labour, machinery, and time constraints. 
Toyota implemented the human resources management system by establishing good communication network for all stakeholders of the company [7]. Employees, supervisors, coordinators, management, and even board of directors are widely given the opportunity to express an opinion or evaluation. In Toyota, a relationship is used as a method of work. Therefore, working on a team is more preferable than working individually [28]. Kaizen greatly minimise waste in various sectors. Efficiency is greatly emphasised in the work process through Kaizen training method. Wastage is considered as the base of a problem within a company. It is assumed that the waste will increase the cost and decrease work effectiveness. It means that Toyota implementings $3 \mathrm{M}$ in the company's operations, namely Muda and Muri.

In addition, Toyota also implement PDCA and $5 \mathrm{~S}$ in running the company. Toyota routinely separates the necessary objects from unnecessary objects to further remove those unnecessary items. That activity is one of examples of the Seiri from $5 \mathrm{~S}$ implementation. Getting rid of items that are not needed in the factory can streamline the production.

In 1981, Motorola was admittedly unable to compete with similar companies in Japan due to its unfavourable design and production quality [21]. The crisis that threatened Motorola's sustainability makes the owner think hard. Refocusing the business by selling a number of operations that did not perform well and side operations were the only options left. In addition, Motorola also renewed its commitment to innovation and new product development.

'Muri' is one of the components of Kaizen which means to reduce the tension within a company. The steps taken by Motorola when experiencing company constraints were to change to the sustainable development-based management system using PDCA (plan-docheck-act) to improve Motorola's competitiveness, hence corporate goals can be achieved [21].

Canon as one of the companies in Japan has also implemented Kaizen to run the company. At that time, each Canon's plant was introduced to a project called the Kaizen 100 projects which required every manager to think of more than 100 different types of everyday tasks that can be improved. The supervisor also has to set as many as 100 kinds of improvements. For that, whenever a manager or supervisor have an idea, they should wrote down their ideas in a form. Supervisors are required to set aside time for half an hour every day from 11.30-12.00 pm local time which referred as Kaizen time, a time where everyone should not do anything except to think about the improvement for each work unit.

Basically, Canon's Kaizen project form has included problem identification columns, identification of the cause of the problem, proposed corrective actions, responsibility, and projected impact. The Kaizen project form can be compiled on the basis of employees' suggestion form or a brainstorming result. Another characteristic that contribute to the success of Kaizen project in Canon was the incentive system for each suggestion according to its weight level. The suggestion system has also been widely adopted by other Japanese companies.

Kaizen's implementation in Canon is well-recognised. This is demonstrated by the circumstances in which Canon receives more than 70 suggestions every year and almost all of the suggestions are executed even though the suggestion is not a great idea [24]. In this case, Canon has generally applied Kaizen where changes are made through small and simple but continuous actions. These activities show that Canon still efficiently produce goods and the production is still sought by the global market share until today.

The 3M, 5S, and PDCA movements have basically been applied in various contexts of Japanese society. Kaizen has been rooted in the Japanese' way of thinking to make improvements, and to strive for better tomorrow. Management and Kaizen are highly related. 
It can be seen that management has two main components, namely maintenance and perfection. Maintenance can be defined as an activity aimed to maintain technological, managerial and operational standards. In the maintenance task, management performs the tasks responsibly therefore everyone in the company can implement the standard operational work.

Employees are required to work according to the standards as set out in SOP. If the employee is unable to perform in accordance to the standards, then management should provide training or revise the standards hence can be implemented by employees. To control the standards, improvement can be done by providing training for employees in order to correspond with the company's target.

Although kaizen has been successfully implemented to improve the company, there are still companies that have not successfully implement the systems within the company's environment. The implementation of kaizen is cannot be done only once, but it has to be applied sustainably (continuous). It is not easy to remember consistency (habituation) requires a change of value within the individual thus it can change the behaviour and becomes a new habit [29].

There was a case in Toyota that related to the failure in the human resource development. Although it was previously known that Toyota is a company that managed to tackle loss by achieving success in their targets as well as the ability to survive in the midst of the global crisis, which makes Toyota recognised as a company that is admired by the world as a result of Kaizen implementation. On the other hand, it was found that individuals who left Toyota later found their new company did not guarantee to achieve the same success compared to Toyota. This is because Kaizen principle applied in Toyota is not seen as a goal, but as a process. Kaizen is a process thus it must be run continuously by every stakeholder. If Kaizen is seen as an objective, there will be no sustainable improvement and optimal results cannot be obtained.

There are several problems in the implementation of kaizen within the company's environment, such as the differences in Japanese's culture with other countries, less intensive relationships between stakeholders as well as the vision and mission which are too short [29]. The desired improvements are not achieved due to these factors, especially the development of employees as the key element to maintain the company in the midst of a volatile condition.

If there is still a less harmonious relationship among stakeholders, it means employees need training to improve the required skills while the company does not provide these facilities, therefore kaizen has been disrupted. Based on this issue, the company has clearly abandoned the 3M i.e. 'mura' and 'muri' which mean to reduce the distinctions and tensions. The distinction that occur is due to the limited relationship in consequence of the job description. Whereas, the concept of kaizen has positioned all stakeholders from the top hierarchy (top management) to the bottom (staff employees) must be involved to realise sustainable development. The duties and responsibilities of each individual in a different division depend on their position. Kaizen requires all individuals to understand the duties and responsibilities of each person to be executed.

Kaizen must start from the owner of the company, in which the owner must be a responsible individual and have full authority to change the company system and capable to explain the system to every element of the company. Thus, kaizen will not succeed without full support from the owner of the company.

It should be pointed out that although kaizen starts from top management (company owner), it requires teamwork process. The awareness of the duties and responsibilities of each individual can lead to a gap between the ability that has been possessed with the ability to be 
achieved, therefore the need arises to improve skills through training. Top management is obliged to provide facilities in the form of training for employees while supervisors perform control function. The team is selected from individuals from various functional divisions. Employees who are given training are those who have potential and viable to improve their skills based on the judgements that has been made.

Therefore, improvement and refinement must be done at any time, which is based on the meaning itself that improvement and refinement are done continuously and sustainably [11]. Kaizen can be started by realising that every company has a problem. It solves the problem by forming a company's culture where everyone can raise the issue freely. Although the improvements are small and gradual, but the process is capable of bringing dramatic results in the course of time.

\section{Conclusions}

Based on the analysis and discussion above, the conclusions of this study are, First, the rapid dynamics brings the effect of changes for the goal of the company, thus it is necessary for human resources to possess related knowledge. The commitment from the top management was not enough to help the company achieve its goals. Therefore, the employee development sustainability is necessary. Second, the kaizen offers the concept and procedure of changes to improve the company. It is not only focusing on the results, but rather to focus on a process that run with regular supervision on the smallest component to the largest within the company where it takes a continuous and sustainable improvements. Therefore, Kaizen is an effective solution to deal with the changes of modernisation. Third, kaizen is reinforced through several concepts of 3M, 5S, and PDCA. Each of the concepts has a light phase and accuracy to be adopted in improving the company. The concept of $3 \mathrm{M}$ is the basis of improvement that will be paired with $5 \mathrm{~S}$. Meanwhile, PDCA covers theory and practice which then performed an analysis or evaluation to make the best decision in running the company.

\section{References}

[1] Mathis, R. L \& Jackson, J. H. Human Resource Management (Thirteenth edition). USA: Cengage Learning, 2011.

[2] Stewart, G. L \& Brown, K. G. H. Human Resource Management (2nd edition) Linking Strategy To Practice. USA: John Wiley \& Sons, Inc, 2011.

[3] Bratton, J \& Gold, J. Human Resoaurce Management Theory and Practice Second Edition. New Jersey: Lawrence Erlbaum Associates, Inc., Publishers, 1999.

[4] Maruta, R. Maximizing Knowledge Work Productivity: A Time Constrained And Activity Visualized PDCA Cycle. Knowledge and Process Management Vol. 19 No. 4 pp 203-214, 2012.

[5] Scullion, H \& Paauwe, J. Edited by Anne-will Harzing \& Joris Van Ruysseveldt. International Human Resource Management: Recent Development in Theory and Empirical Research. London: Sage Publication, 2004.

[6] Kulkarni, M. P. P. A Literature Review On Training \& Development and Quality Of Work Life. International Refered Research Journal Vol. 4 No. 2 pp 136-143, 2013.

[7] Marksberry, P. 2013. The Modern Theory of The Toyota Production System. Paris: CRC Press, 2013.

[8] Teplika, K \& Culkova, K. Kaizen And Its Applying During Cost Decreasing In Process Of Production Firm Maintenance. International Journal Of Engineering Vol. 9 No. 3 pp. 315-318, 2011. 
[9] Singh, J \& Singh, H. Continuous Improvement Approach: State-Of-Art Review And Future Implications. International Journal Of Lean Six Sigma Vol. 3 No. 2 pp. 86-111 DOI:10.1108/20401461211243694, 2012.

[10] Bhoi, J. A., Desai, D. A., Patel, R. M. The Concept \& Methodology of Kaizen. International Journal of Engineering Development And Research Vol 2 No. 1 pp. 812 $820,2014$.

[11] Delers, A In Collaboration with Feys, B Translation by Probert, C. Kaizen Plan-DoCheck-Act. Lemaitre Publishing, 2015

[12] Cehlar, M., Teplika, K., Szabo, S. Kaizen - New Instrument For Process Of Maintenance In Air Force. International Conference of Scientific Paper Afases 2011 pp. 1075-1080, 2011.

[13] Chaudari, T \& Raut, N. Waste Elimination by Lean manufacturing. UISET International Journal of Innovative Science, engineering \& Technology Vol. 4 No. 5 pp. 168-170, 2016.

[14] Rabakavi, H., Ramakrishna, H. Baligar, S. Thorough Elimination Of Mura, Mura And Muda To Achieve Customer Satisfaction. International Journal Of Innovative Research \& Development Vol. 2 No. 5 pp. 1457 - 1469, 2013.

[15] Gupta, S., Sharma, M., Meshram, S. Productivity Improvement in Light \& Medium Duty Chassis Assembly Line At Ve Commercial Vehicle. International Journal Of engineering Sciences \& Research Technology pp. 190-194, 2015.

[16] Chitre, A. R. Implementing 5S Methodology for Lab Management In The Quality Assurance Lab of a Flexible Packaging Converter. Mnemonia: University of Wisconsin-Stout, 2010.

[17] Chapman, C. D. Lean: Clean House With Lean 5S. New York: TUV Insight Editing, 2005.

[18] Dulhai, G. The ' $5 \mathrm{~S}$ ' Strategy For Continous Improvement Of The Manufacturing Processes In Autocar Exhaust. Journal of Management \& Marketing Vol. 3 No. 4 pp. 115-120, 2008.

[19] Dewi, S. R., Setiawan, B., Nugroho, S. W. P. 5S Program To Reduce Change-Over time On Forming Department (Case Study On CV Piranti Works Temanggung). IOP Conference Series: Materials Science and Engineering pp. 1-10 doi:10.1088/1757899X/46/1/012040, 2013.

[20] Dudin, M. N., Frolova, E. E., Gryzunova, N. V., Shuvalova, E. B. The Deming Cycle (PDCA) Concept As An Efficient Tool For Continous Quality Improvement In The Agribusiness. Asian Social Science Vol. 11 No. 1 pp. 239-246 doi:10.5539/ass.v11n1p239, 2015.

[21] Gupta, P. Process Management: Beyond PDCA-A New Process Management Model. pp. 45-52 https://www.researchgate.net/publication/259497347, 2006.

[22] Johnson, C. N. The Benefits of PDCA: Use This Cycle For Continual Process Improvement. Milwaukee: ASQ Quality Press, 2002.

[23] Sokovic, M., Pavletic, D., Pipan, K. K. Quality Improvement Methodologies - PDCA Cycle, Radar matrix, DMAIC And DFSS. Journal Of Achievement In Materials And Manufacturing Engineering. Vol 43 No. 1 pp. 476-483, 2010.

[24] Jalu, G. Achievement of Quality, Productifity For Market Through kaizen Implementation In Eithiopia. Arabian Journal Of Business And Management Review Vol. 6 No. 1 pp. 1-8, 2015.

[25] Kucinska, A \& Landwojtowicz. Dterminants Of The Concept Of Continous Improvement In Manufacturing Company- Case Study. Research/Expert Conference 
With Internatioanl Participations “QUALITY 2015”, Neum B \& H, June 10 -15. Pp. 15 $-20,2015$.

[26] Stefanic, N., Tosanovic, N., Hegedic, M. Kaizen Workshop as an Important Element Of Continuous Improvement Process. International Journal Of Industrial Engineering and Management (IJIEM) Vol. 3 no. 2 pp. 93-98, 2012.

[27] Jaca, C., Viles, E., Galeano, L. P., Santos, J., mateo, R. Learning 5S Principles From Japanese Best Practitioners: Case Studies Of Five Manufacturing Companies. International Journal Of Production Research Vol. 52, No. 15 pp. 4574-4586 doi.org/10.1080/00207543.2013.878481, 2015.

[28] Vidova, H. Lean Logistic - The Important And Utilisation In Slovak Industrial Practice. Research Papers Faculty Of Materials Science And Technology In Trnava No. 27 pp. 119 - 126, 2009.

[29] Drljaca, M, External Context Of The Organization. Journal Of Mecanical Engineering Vol. 12 No. 1-2 Pp. 3-15, 2015. 